\title{
The acoustical improvement plan as a process to re-establish acceptable acoustical conditions
}

\author{
M. Clerico \& G. Soffredini \\ Politecnico di Torino, DITAG, Torino, Italy
}

\begin{abstract}
The word "Acoustical Improvement Plan" indicates a set of provisions, related to land management and suitable to reach the targets defined in the planning, with particular reference to acoustical standards satisfaction.

The acoustical improvement plan could be interpreted as a loosening of the most critical nodes checked by the comparison between the noise mapping and the acoustical characterisation of a territory, but this interpretation could not reply to the most diffused question of acoustical quality. This condition derives by an approach founded on a multiplicity of actions and provisions, able to implement new logics in decisional processes that determines the territory planning and manages the transformation, with a particular attention to environmental noise problems.

The purpose of this paper is to describe the plan identity, which isn't represented by a specific planning action, but it invests and interests in particular actions of all politics of planning and territorial management, involving therefore the necessity to coordinate and to interact with the main instruments of territorial management.

The acoustical improvement plan will not be the design of the intervention aimed to restore the sound levels limits, but a process, structured as a set of provisions and principles of urban planning and government of the territory, with the purpose to re-establish acceptable acoustic conditions for the critical zones, but also in order to prevent eventual future suffering.

Keywords: noise pollution, acoustical improvement plan, environmental planning, land management.
\end{abstract}




\section{The characteristics due to a healing plan}

The word "Acoustical Improvement Plan" indicates a set of provisions, related to land management and suitable to reach the targets defined in the planning, with particular reference to acoustical standards satisfaction.

A healing plan could be made of different measures, as administrative, legislative and through intervention to reduce environmental noise.

The accordance of these procedures indicates a healing plan as a project that requires an interaction and coordination among the most important instrument of environmental management.

The most strategic interaction could be with the functions asked to plan and manage the traffic and related infrastructures.

The plan identity is not recognized in a specific action of a specific project, but involves intentions and actions of the whole politics of the territorial management [1].

This need of coordination, does not remain an internal request of Local Administrator, but becomes essential when other Subjects have to prepare and project a healing plan for the acoustical and environmental improvement.

The healing plan is not the intervention project to take the acoustical value into law limits, but a whole of coordinate intervention for the progressive improvement. The interventions have to be different as type, time and related to specific part of territory or specific sources. The plan aimed to these objectives is not a project describing works, but a process, fixing structure and administrative conditions that determine a progressive acoustical improvement [2].

\section{The contents of the Municipal Acoustic Improvement Plan (PRAC)}

An acoustical improvement plan (PRAC) is the result of the comparison between the territorial PCA, "acoustic classification plan" (municipal action mandatory for the Italian law LQ 447/95) and the relevant survey: it must represent a solution of the most critical issues and the recovery actions have to answer to an extensive acoustic quality request which can only be the outcome of an integrated approach leading to the implementation of new specific strategies focused on the environmental noise and aimed to the territory management and evolution.

The improvement plan will therefore be based on a wide actions range not only finalized to the mitigation of specific limits overcoming, but mainly intended as a coherent project where at the same time mitigations of the most critical situations, urban development plans, territorial government and administration will act to restore an acceptable acoustic situation and to prevent future problems.

The correct approach to the acoustical improvement plan is therefore to put in place a set of effective activities, extending the application range from the reduction of the environmental noise intensity from fixed an mobile sources, to the mitigation of the acoustic impact on the affected people and to the 
optimization of the passive protection performances of the buildings where the human activities are carried out, starting from the most sensitive situations. In this logic the technical and design actions to be developed in an improvement plan can be targeted to:

- $\quad$ noise emission reduction (source matrix reduction)

- receivers exposure reduction (propagation path countermeasures)

- buildings passive protection improvement (where sensitive activities are located) [1].

\section{The applied interaction between noise and land management}

The PRAC is a dynamic tool in the acoustic pollution management and control, which includes design and direct mitigation capabilities always based on administrative actions, territorial (town planning and acoustics) and mobility management, through mandatory carry-back on actuation regulations [3].

Therefore administration, legislation and regulations aspects represent the core of the plan finalized to containment and mitigation of already compromised situations: such a scope requires interactions and coordination with the other territorial management tools and with current regulations.

Even if the PRAC is not intended to produce administrative measures or urban development plans, this instrument must be used as an integration tool to include the acoustical impacts analysis on the territory, showed into "acoustic classification plan" PCA, and finalize proposals for future development. This point can be developed by the identification of procedures, operative tools and processes for the monitoring of acoustic effects related to different options, or through the comparison of acoustical effects of alternative scenarios.

This can for example applied to the development of the City (PRGC) and Mobility plans and to the definition of the acoustical optimization criteria, or define references to be used in administrative measures finalized to the traffic management (such as Limited Traffic Zone (ZTL), heavy vehicles traffic, speed limitation along specific city areas).

Due to the important role the territorial government plays especially on mobility, the contribution of the improvement plan also accounting for environmental acoustic quality can be regarded as a significant issue both in terms of recovery and prevention.

Also the normative aspects can provide an essential contribution, in addition to the administrative ones, with specific reference to the prevention of further problems (i.e. the European Directive of 1996 about IPPC "Integrated Pollution Prevention and Control", including noise pollution problems).

The normative horizon of the improvement plan is deployed through a coherent program involving the local administration government, also including integrative instructions for building codes, health and safety issues and municipal police regulations about "noisy activities". 
In fact, as far as the building codes are concerned, the building codes refer to the passive acoustic requirements to be specified as a function of use, construction characteristics, infrastructural situation, and acoustic impact documentation to be attached to the authorization request.

The integration of the operative technical specifications into the city plan plays a major role in territory government, through regulations finalized to the implementation of the acoustical classification as a tool in urban and building evolution [2].

Table 1: Scheme for the applied interaction between noise and land managements.

\begin{tabular}{|c|c|c|c|}
\hline & \begin{tabular}{|l|} 
Administration \\
Planning Actions \\
\end{tabular} & $\begin{array}{l}\text { Laws and } \\
\text { Codes }\end{array}$ & \begin{tabular}{|l|} 
Operative \\
Actions \\
\end{tabular} \\
\hline $\begin{array}{l}\text { Reduction of noise } \\
\text { emissions in the } \\
\text { environment }\end{array}$ & $\begin{array}{l}\text { - } \text { City Plan (PRGC) } \\
\text { - Acoustic } \\
\text { Classification Plan } \\
\text { (PCA) } \\
\text { - Mobility City } \\
\text { Planning (PUT) } \\
\text { - Infrastructural } \\
\text { PRAC } \\
\text { - Private PRAC } \\
\text { IPPC }\end{array}$ & $\begin{array}{l}\text { European, } \\
\text { National and } \\
\text { Local laws }\end{array}$ & $\begin{array}{l}\text { - Impact Noise } \\
\text { Assessment } \\
\text { - ZTL } \\
\text { - Transport } \\
\text { Noise Mapping }\end{array}$ \\
\hline $\begin{array}{l}\text { Mitigation of impact } \\
\text { on exposed people }\end{array}$ & $\begin{array}{l}\text { - City Plan (PRGC) } \\
\text { - Strategic Noise } \\
\text { Mapping } \\
\text { - Noise Exposure } \\
\text { Assessment }\end{array}$ & $\begin{array}{l}\text { European, } \\
\text { National and } \\
\text { Local laws }\end{array}$ & $\begin{array}{l}\text { - } \text { Noise } \\
\text { Conditions } \\
\text { Assessment } \\
\text { - Private PRAC }\end{array}$ \\
\hline $\begin{array}{l}\text { Improvement of } \\
\text { passive protection } \\
\text { performances on } \\
\text { receivers }\end{array}$ & - Building Codes & $\begin{array}{l}\text { National laws } \\
\text { and codes }\end{array}$ & $\begin{array}{l}\text { - Passive Noise } \\
\text { Building } \\
\text { Assessment }\end{array}$ \\
\hline
\end{tabular}

\section{The application of the improvement plans: case histories}

The national Italian legislation (LQ 447/95 and actuation decrees) establishes the need of municipal improvement plans and private company improvement plans for specific sources as transportation infrastructures and production sites under specified conditions: such conditions are identified when pre-existing problems are to be recovered.

In particular, for the private company and transportation infrastructure improvement plans (DM 29/11/2000) [6] the intervention is required when the emission limits, defined by PCA, are overcome. 
Differences are addressed as a function of the operational areas:

- Municipalities: the acoustic improvement plan represents a complete process, involving different competencies, regarding the whole city asset, town planning, administration, production and transportation infrastructures.

- Transportation infrastructures and production sites: in case of environmental acoustical pollution generated by a source are committed to restore the pre-existing compatibility acting on the source (when sustainability is not achievable) with specific containment actions.

As far as the municipal plans are concerned, the authority intervention is mandatory when the warning limits are overcome (LQ 447/95, art. 2, comma 1, lett. G) which in long term perspective coincides the emission limits of the PCA or in case of borderline connection between urban areas having quality levels with more than $5 \mathrm{~dB}$ (A) discrepancy. A case history of the last condition is showed in the Figure 1, where a discrepancy is caused by an industrial plan into the residential zone.

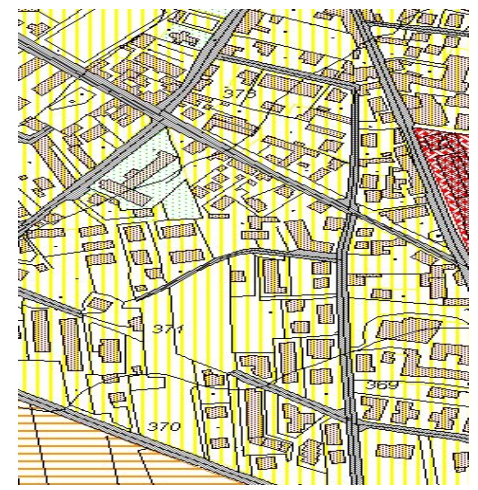

Figure 1: Example of the urban area where PRAC is mandatory: case of borderline connection between urban areas having in PCA quality levels with more than $5 \mathrm{~dB}(\mathrm{~A})$ discrepancy, caused by an industrial plan into the residential zone.

The plans are also managed by different authorities who are required to deliver a fully exhaustive result homogeneous across the whole territory.

From this point of view, it is easier to check the need and the validity of a production site improvement plan compared with the plan for a transportation infrastructure where is far more difficult to define the right counterpart authority: at municipal level the local government is competent for the whole territory except the pertinence bands of the transportation infrastructures.

As mentioned, the municipal improvement plan process can be activated by the administrations in case of need (limits overcoming or acoustically non compatible boundary conditions) but also when an acoustic quality target is to be 
achieved. This characteristic is in line with and anticipates the UE regulation, which supports the need to preserve the good acoustical areas.

Indeed, the authority intervention is discretional when the local administration wants to reach a fixed quality level, even if the warning thresholds are not overcome or he needs to co-ordinate and to manage different private or/and infrastructural acoustical improvement plans (i.e. Figure 2).

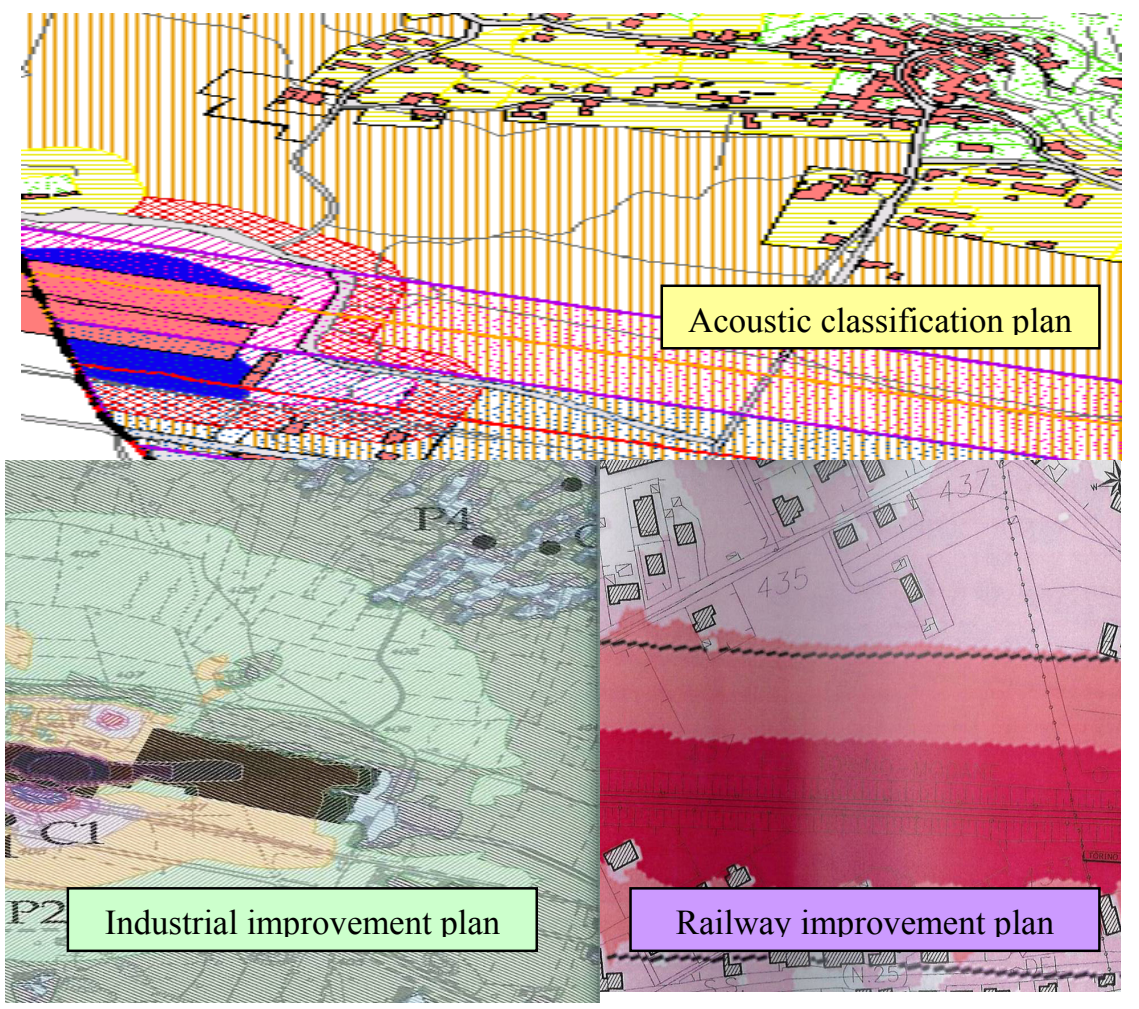

Figure 2: Case history of a discretional PRAC of an urban area: the residential part of the town does not need any improvement actions, but the industrial and the railway noise sources require specific acoustical improvement plans.

The Italian legislation addresses the general PRAC contents and the activation procedures and criteria are still undefined. The PRAC is by definition a dynamic instrument whose effectiveness depends on the checking and updating work to be carried out according with a pre-defined timing, to allow the efficient revision of the achieved results (and their validity) and of course to monitor the on going activities.

The main open points refer to inter-functional relationship with the transportation infrastructures and private companies and the correlation mechanisms with the other town planning and territory management tools. 
The Italian law deals with the transport noise pollution [4], allowing in the pertinence band of roads and railways (until $100-250 \mathrm{~m}$ of wildness from the centre of the infrastructure line) emission values higher than safety noise limits as defined in the PCA.

Therefore, from the legal point of view, if the noise does not exceed the legal infrastructure noise limits, the PRAC is not mandatory, also in case of strong noise exposure and pollution.

However, if the objective is to reach the safety conditions of people exposure, by respecting the noise limit values as indicated by WHO, the PRAC is needed and is a precondition in any situation of noise pollution, even if the legal limits are formally respected.

In figure 3 is showed a case history of an urban area where one national road, one highway and one railway generate, in particular in the night period, the noise values incompatible with the people safety conditions, without exceeding the Italian law limits for transport noise. In this case PRAC is not legally mandatory, but is the precondition to reach the required improvement in terms of people noise exposure.
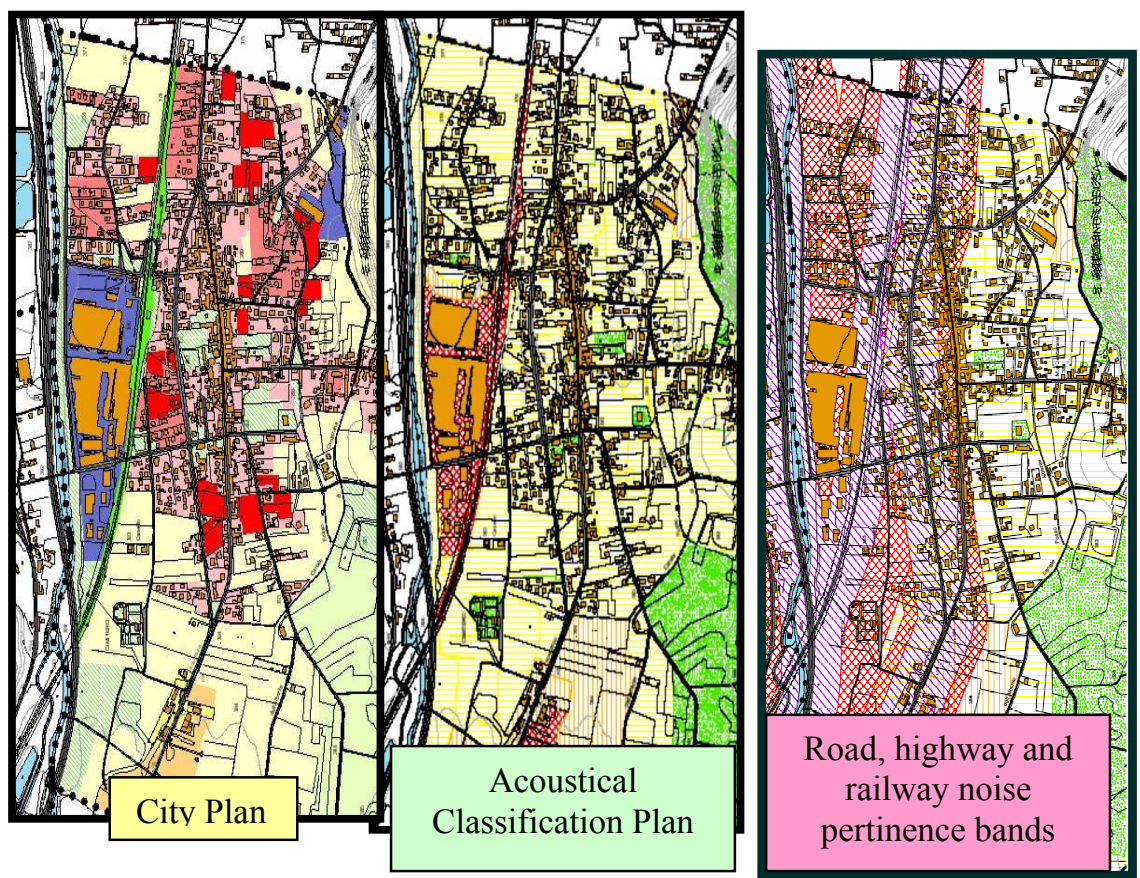

Figure 3: A case history of an urban area where one national road, one highway and one railway generate, in particular in the night period, the noise values incompatible with the people safety conditions, without exceeding the Italian law limits for transport noise. In this case PRAC is not legally mandatory, but is the precondition to reach the required improvement in terms of people noise exposure. 


\section{How to integrate the national and UE action plan levels?}

It is evident that, in urban areas strongly affected by the transportation noise pollution (i.e. figure 4), no effective short/medium term prevention are actually achievable and therefore it becomes mandatory to manage the territory development together with the infrastructures to and obtain at least long term improvements in population exposure conditions. This approach had been adopted by UE requiring jointed actions from the national communities.

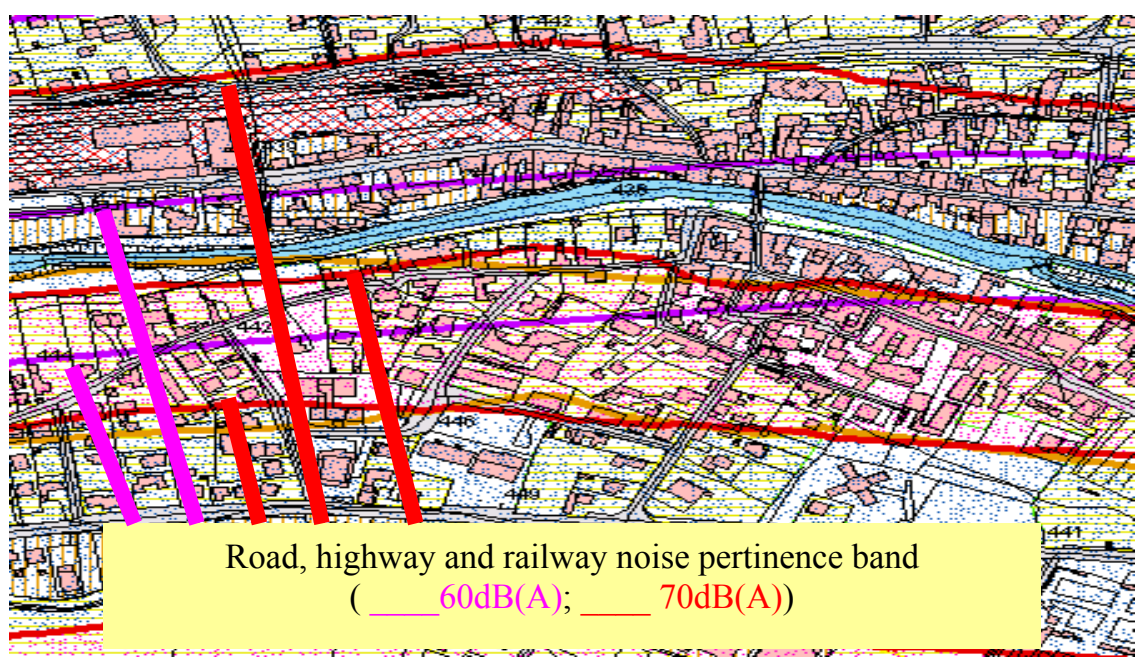

Figure 4: A case of an urban areas strongly affected by the transportation noise pollution where it becomes mandatory to manage the territory development together with the transport actions.

The tool for acoustic pollution and the associated problems management is defined in the action plan, which must be developed to account for urban areas and for the transportation infrastructures, with a timing plan depending on the dimensions of the involved area.

The UE standards do not contain a detailed specification of a plan, but underline the priorities whose identification depends on limits overcoming. The application of such a tool is related with the strategic mapping which is the knowledge instrument intended to define the acoustic situation.

The relationship between the National and the European tools is realized with the acknowledgment of the DIR 2002/49/CE [5] through the legislative decree 19 AGOSTO 2005, N.194 [6].

Such a decree defines the competencies and the procedures for the elaboration of the acoustical mapping and of the acoustical strategic maps, as fundamental instruments to define the existing acoustic situation.

The Acoustical Strategic Maps is a map finalized to the definition of the global exposition to noise in a certain area due to various noise sources, or to define the general forecast for such an area. 
The Acoustic Mapping (which is required for transportation infrastructures) consists in the representation of data describing an existing or forecasted noise situation in an area, generated by a specific source, as a function of an acoustic parameter showing the overcoming of the applicable limits together with the number of exposed people or the number of houses exposed to a determined level.

From the above definitions it is clear that the acoustical strategic map represents the noise emissions while the acoustic map describes the acoustical emission of specific sources.

The acoustic mapping and the strategic acoustical maps finally represent data describing an existing noise situation and the relevant exposure: both types can be presented as graphs or diagrams.

The directive application field appears different from the Italian laws: if, according the national law, it is necessary to design healing plans for all the Municipalities (consequent to the application of the acoustic classification of the territory) in the European normative action plans are demanded for the big agglomerates and for the transport infrastructures.

Differences are minimal for the infrastructures, for which a study of the acoustical emission (also in term of acoustical map) and a healing plan is required: the European directive doesn't include the road infrastructures $<3000$ vehicles/year and the rail infrastructures $<30.000$ passages/year.

There are important differences between European and Italian law considering about the environment of life, because the Italian law includes all the towns in the necessity of the healing plans, but are included in the European Directive only the agglomeration having population in excess of 100.000 persons and a population density that the Member State considers it to be an urbanised area.

The distribution of the Italian population, divided in little or medium dimension town, should implicate a reduced impact for the European norm, with many realities excluded by an intervention of acoustical healing.

In spite of what above stated, the action plans defined by UE should constitute the guide lines about the transport noise analysis for what refers to the acoustical improvement plan (PRAC) and represent an important integration of the land management in all urban areas.

\section{Conclusions}

The aim of the European Directive and of the Italian law shall be to preventing and reducing environmental noise where necessary and to preserving environmental quality where it is good.

The analysis of the environmental noise and its representation in term of maps, the evaluation of the population noise exposure are the novelty in the Italian regulation.

Because the objective is to reach the safety conditions of people exposure, by respecting the noise limit values as indicated by WHO, the acoustical 
improvement plan (PRAC) is needed and precondition in any situation of noise pollution, even if there is the formal respect of the legal limits.

The healing plan, beyond the content of the single measure, express the theme of the acoustical quality in the local administration's culture and it represents a systematic instrument of political addresses and concrete actions, to support the choices of territory management and its activities.

In fact, a territorial planning integrated with the acoustical management instruments, through a correct urbanite planning, should permit to eliminate from the beginning the critical situations. The healing plan is not an instrument to improve compromise situations or a set of passive protection interventions on the buildings.

These solutions are obviously necessaries where an incorrect urbanite planning, in acoustical terms, has generated situations solvable only with a rilocalization, not easily realizable.

\section{References}

[1] ANPA Agenzia Nazionale Per La Protezione Dell'Ambiente "Linee guida per l'elaborazione di piani comunali di risanamento acustico", a cura di ANPA, APPA Bolzano, APPA Trento, ARPA Emilia Romagna, ARPA Liguria, ARPA Valle d'Aosta, ARPA Veneto, ARPA Toscana, Regione Lombardia, 1998

[2] Alberto Muratori "Piani di risanamento acustico: dimensione amministrativa, pianificatoria e normativa", Convegno Nazionale "I piani di risanamento delle aree urbane", Modena 22 - 23 febbraio 1999, in Atti pp 3- 17

[3] Jacopo Fogola, Rosario Romano "Piani d'azione e piani di risanamento acustico", Convegno Nazionale "La direttiva 2002/49/CE: Determinazione e gestione del rumore ambientale e suo impatto sulla legislazione italiana"Pisa, 18 novembre 2004, in Atti pp. 71-81.

[4] Decreto del Ministero dell'Ambiente 29/11/2000 “Criteri per la predisposizione, da parte delle società e degli enti gestori dei servizi pubblici di trasporto o delle relative infrastrutture, dei piani degli interventi di contenimento e abbattimento del rumore"

[5] Direttiva 2002/49/CE del Parlamento Europeo e del Consiglio relativo alla "Determinazione e gestione del rumore ambientale"

[6] Decreto legislativo 19 agosto 2005, n.194 "Attuazione della Direttiva 2002/49/CE relativa alla determinazione e alla gestione del rumore ambientale" 